\title{
Patterns of ancestry and genetic diversity in reintroduced populations of the slimy sculpin: implications for conservation
}

\author{
David D. Huff • Loren M. Miller • Bruce Vondracek
}

Received: 11 February 2010/Accepted: 10 August 2010/Published online: 6 September 2010

(C) US Government 2010

\begin{abstract}
Reintroductions are a common approach for preserving intraspecific biodiversity in fragmented landscapes. However, they may exacerbate the reduction in genetic diversity initially caused by population fragmentation because the effective population size of reintroduced populations is often smaller and reintroduced populations also tend to be more geographically isolated than native populations. Mixing genetically divergent sources for reintroduction purposes is a practice intended to increase genetic diversity. We documented the outcome of reintroductions from three mixed sources on the ancestral composition and genetic variation of a North American fish, the slimy sculpin (Cottus cognatus). We used microsatellite markers to evaluate allelic richness and heterozygosity in the reintroduced populations relative to computer simulated expectations. Sculpins in reintroduced populations exhibited higher levels of heterozygosity and allelic richness than any single source, but only slightly higher than the single most genetically diverse source population.
\end{abstract}

Electronic supplementary material The online version of this article (doi:10.1007/s10592-010-0124-6) contains supplementary material, which is available to authorized users.

D. D. Huff $(\bowtie)$ L L. M. Miller · B. Vondracek

Department of Fisheries, Wildlife and Conservation Biology,

University of Minnesota, 1980 Folwell Avenue,

200 Hodson Hall, Saint Paul, MN 55108, USA

e-mail: huffx056@umn.edu

L. M. Miller

e-mail: mille075@umn.edu

B. Vondracek

e-mail: bvondrac@umn.edu

B. Vondracek

USGS, Minnesota Cooperative Fisheries and Wildlife Research

Unit, University of Minnesota, Saint Paul, MN, USA
Simulations intended to mimic an ideal scenario for maximizing genetic variation in the reintroduced populations also predicted increases, but they were only moderately greater than the most variable source population. We found that a single source contributed more than the other two sources at most reintroduction sites. We urge caution when choosing whether to mix source populations in reintroduction programs. Genetic characteristics of candidate source populations should be evaluated prior to reintroduction if feasible. When combined with knowledge of the degree of genetic distinction among sources, simulations may allow the genetic diversity benefits of mixing populations to be weighed against the risks of outbreeding depression in reintroduced and nearby populations.

Keywords Genetic diversity - Conservation genetics · Genetic variation - Native fish conservation - Restocking · Translocation

\section{Introduction}

Reintroductions that attempt to re-establish a species within its historical range (IUCN 1998) are a common approach for preserving intraspecific biodiversity in fragmented landscapes (Fischer and Lindenmayer 2000; Seddon et al. 2007). However, reintroduced populations are generally smaller and more isolated than native populations. Reintroductions may therefore exacerbate the genetic erosion initially caused by population fragmentation by reducing the effective population size (Lande and Barrowclough 1987) of both the source and reintroduced populations (Griffith et al. 1989; Wolf et al. 1996). Several studies have documented significant reductions in the genetic variability of reintroduced populations relative to their source 
(Fitzsimmons et al. 1997; Mock et al. 2004). Reduced genetic variation may decrease evolutionary potential, reduce ability to fight off disease, and increase other harmful effects of inbreeding (Keller and Waller 2002).

A reintroduction method employed to increase genetic variability is to mix genetically divergent source populations (Tallmon et al. 2004; McClelland and Naish 2007). In addition to helping avoid the negative effects of inbreeding, intraspecific hybridization is thought to impart a high degree of adaptive potential for the novel ecological situations that often occur at reintroduction sites (Lesica and Allendorf 1999; Jones 2003). However, there are at least two potential disadvantages associated with mixed sources. First, hybridization between genetically disparate individuals may result in a decline in fitness of the offspring, referred to as outbreeding depression (Edmands 2007; McClelland and Naish 2007). Mechanisms implicated in outbreeding depression may be "intrinsic," due to the breakdown of co-adapted gene complexes in hybrid progeny that result in the loss of adaptive traits that significantly affect survival (Templeton et al. 1986). Whereas "extrinsic" mechanisms for outbreeding depression occur when each parent is locally adapted to different ecological conditions; the offspring may have an intermediate phenotype, rendering them less fit in either parental environment. Second, mixing source populations may disrupt the genetic distinctiveness of populations (Moritz 1999; Jones 2003). Preserving the intraspecific variation present across a species' range is widely accepted as a critical conservation priority, and the loss of genetically distinct populations is considered by some to be as significant as the loss of entire species (Ehrlich 1988; Foster et al. 2003). From a restoration standpoint, preserving genetic distinctiveness is desirable to protect the ecological and genetic processes in neighboring communities and in remnant conspecific populations that may be influenced by gene flow from the reintroduced population.

There is a troubling decline of indigenous freshwater fish populations in North America (Miller et al. 1989; Minckley and Deacon 1991; Jelks et al. 2008) and reintroductions have been included as part of more than $80 \%$ of the recovery plans for threatened and endangered species and continue to be important (Williams et al. 1988; George et al. 2009). Although most endangered and rare species exist as small, isolated populations (Holsinger and Gottlieb 1989), populations of common species are becoming fragmented and isolated as well. The loss of genetic diversity within species that have small, fragmented populations due to habitat destruction is a major concern in species conservation (Lande 1988, 1998). Our study organism, the slimy sculpin (Cottus cognatus), tends to be locally abundant (Bond 1963; Petrosky and Waters 1975), but is a relatively poor disperser (Schmetterling and Adams
2004). Contrary to the biased view of rare species extirpation as a result of habitat destruction, abundant species can be among the first to be locally extirpated. Although common species tend to be superior competitors in a given habitat, they may be vulnerable because of poor dispersal abilities (Tilman et al. 1997). Furthermore, common species have been shown to be at least as susceptible to the genetic consequences of habitat fragmentation as rare species (Honnay and Jacquemyn 2007).

It is important to assess founder effects of reintroduction practices on genetic variation and evaluate alternatives that could alleviate undesired consequences, yet there are relatively few studies of the effects of reintroductions on genetic diversity or the number and identity of founders that contributed to newly established populations (Latch and Rhodes 2005). Our study documents the ancestral composition and genetic variation resulting from mixedsource reintroductions of slimy sculpin at nine distinct stream sites that are in close geographic proximity. We completed genetic analyses from the source and reintroduced populations using eight microsatellite loci to achieve three objectives: (1) to compare the levels of heterozygosity and allelic richness relative to modeled expectations; (2) to quantify the proportional source ancestry of the populations, as well as the ancestry of individual fish, and compare these to the originally stocked proportions; and (3) to characterize the genetic relationships of the reintroduced populations relative to the source populations. Because a number of isolated and easily sampled populations were available, this reintroduction program provided a unique opportunity to understand post-reintroduction processes and evaluate options for future reintroductions that may improve conservation practices for native fishes.

\section{Methods}

\section{Study organism}

The slimy sculpin is a small $(<130 \mathrm{~mm})$, cryptic, freshwater fish that occupies benthic habitats in lakes, rivers, and small streams. The range of slimy sculpin extends from Virginia, USA to Labrador in eastern Canada and northwest across Canada to eastern Siberia (Scott and Crossman 1979). Cottus spp. are often locally abundant and are frequently a prominent constituent of ecosystems suited to trout and other coldwater fish (Petrosky and Waters 1975; Goyke and Hershey 1992). Slimy sculpins in the study region spawn once per year during the early spring beginning at age II, or rarely at age I, and may live up to 6 years, although few are greater than age III (Petrosky and Waters 1975).

Slimy sculpin populations in southeastern Minnesota occur at the warmer southern limits of their range. They are 
limited by sparse thermal habitat in the small reaches of stream near cold perennial groundwater inputs. As a result, these populations are isolated from other populations making them potentially susceptible to local extinction through risks, such as catastrophic events or inbreeding depression as demonstrated in other animal populations (Saccheri et al. 1998; Bailey et al. 2007). Anthropogenically triggered shifts in hydrologic regimes could cause slimy sculpins, which require a constant source of cold water, to disappear or struggle to survive at the peripheries of their range where thermal clines are of great consequence (Meisner 1990a; Magnuson and Destasio 1997).

\section{Study area and reintroduction project}

The study area (Fig. 1) is located in the Driftless Region of southeast Minnesota, USA. This region is characterized by steep-sided ridges, caves, limestone and sandstone bluffs, sinkholes, and $5,800 \mathrm{~km}$ of spring creeks fed by limestone and sandstone aquifers that eventually drain into the Mississippi River (Tester and Keirstead 1995). The area remained free of ice during the most recent glacial maxima, despite the expansion of the Laurentide ice sheet much farther to the south (Holliday et al. 2002).

Prior to major settlement by European immigrants beginning in 1850, nearly all of the spring-fed streams in the region held trout and presumably slimy sculpins. In subsequent years, slimy sculpin and other cold-water fish abundance declined because of overexploitation and severe habitat degradation (Waters 1977; Leopold and Sewell 2001). Since the 1940s, the Minnesota Department of Natural Resources (MNDNR) and other organizations have completed hundreds of in-stream and watershed improvement projects. These projects stabilized eroding banks, narrowed streams to increase velocity and depth, improved instream substrates, increased fish cover, and increased riparian tree abundance to help maintain cool water temperatures (Waters 1977; Thorn et al. 1997; MNDNR 2003).

In locations where the habitat has been restored sufficiently, MNDNR personnel recently reintroduced slimy sculpins. The goal was to reestablish viable, self-sustaining populations where native populations were likely present historically, but were extirpated. Beginning in 2003, nine streams in the study area (Table 1; Fig. 1) were stocked with a mixture of sculpins from three source streams. The source streams are small tributaries within separate subdrainages that enter the Mississippi River along approximately 40 river kilometers. Stocked fish were randomly selected from each of the source streams for translocation, but young-of-the-year fish were generally avoided. Prior to stocking each year, sculpins were collected from the source streams and subsequently examined by MNDNR fish pathology lab personnel for evidence of diseases to verify that translocated sculpins would not transmit pathogens to fish living in recipient streams.
Fig. 1 Source (filled circle) and recipient (filled triangle) sites in southeast Minnesota. The Driftless Region where study sites are located is shown in the inset superimposed on a map of the United States and indicated by the cross-hatched area covering portions of Minnesota, Wisconsin, Iowa, and Illinois

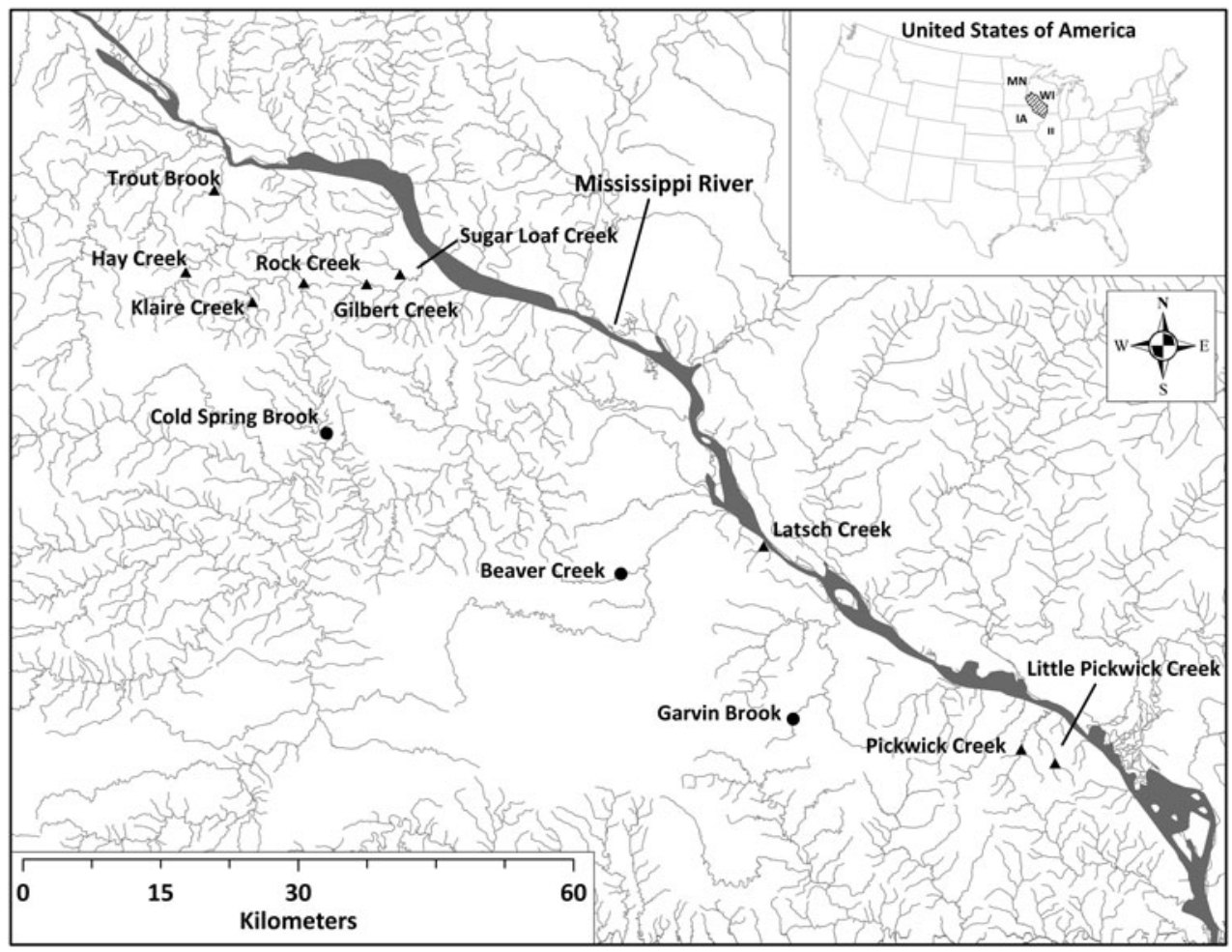


Table 1 Stocking history for slimy sculpin reintroductions and observed and potential genetic diversity

\begin{tabular}{|c|c|c|c|c|c|c|c|c|c|c|}
\hline \multirow[b]{2}{*}{ Population } & \multicolumn{3}{|c|}{ Stocking history for slimy sculpin reintroductions $\mathrm{s}^{\mathrm{a}}$} & \multicolumn{7}{|c|}{ Observed and potential genetic diversity ${ }^{\mathrm{b}}$} \\
\hline & 2003 & 2004 & 2005 & $n$ & Overall $\mathrm{F}_{\mathrm{IS}}$ & $\mathrm{H}_{\mathrm{E}}$ & $\mathrm{H}_{\mathrm{O}}$ & Simulated H & Richness & $\begin{array}{l}\text { Simulated } \\
\text { richness }\end{array}$ \\
\hline Cold Spring Brook (s) & & & & 91 & -0.05 & 0.26 & 0.27 & - & 2.2 & - \\
\hline Garvin Brook (s) & & & & 98 & -0.01 & 0.52 & 0.53 & - & 4.1 & - \\
\hline Beaver Creek (s) & & & & 100 & -0.02 & 0.58 & 0.60 & - & 5.9 & - \\
\hline Latsch Creek (r) & - & $150(75 \mathrm{~B}, 75 \mathrm{G})$ & 150 & 149 & 0.00 & 0.61 & 0.61 & 0.67 & 5.8 & 7.1 \\
\hline Sugar Loaf Creek (r) & - & $150(75 \mathrm{~B}, 75 \mathrm{G})$ & 150 & 168 & -0.03 & 0.67 & 0.68 & 0.68 & 5.9 & 7.1 \\
\hline Klaire Creek (r) & - & $160(76 \mathrm{~B}, 84 \mathrm{G})$ & 150 & 117 & -0.04 & 0.68 & 0.70 & 0.67 & 6.2 & 7.1 \\
\hline Hay Creek (r) & 150 & $155(80 \mathrm{~B}, 75 \mathrm{G})$ & 150 & 150 & 0.05 & 0.68 & 0.65 & 0.69 & 6.3 & 7.2 \\
\hline Rock Creek (r) & - & 149 (75B, 74G) & 150 & 135 & 0.02 & 0.66 & 0.65 & 0.68 & 6.4 & 7.1 \\
\hline Trout Brook (r) & 150 & $140(76 \mathrm{~B}, 64 \mathrm{G})$ & 150 & 172 & 0.00 & 0.68 & 0.68 & 0.69 & 6.5 & 7.2 \\
\hline Gilbert Creek (r) & 150 & $165(70 B, 75 G, 20 \mathrm{C})$ & 150 & 183 & -0.02 & 0.68 & 0.70 & 0.70 & 6.7 & 7.2 \\
\hline Little Pickwick (r) & - & - & 150 & 190 & 0.06 & 0.70 & 0.67 & 0.70 & 7.0 & 7.2 \\
\hline Pickwick Creek (r) & - & - & 150 & 92 & -0.02 & 0.70 & 0.70 & 0.70 & 7.2 & 7.2 \\
\hline
\end{tabular}

${ }^{a}$ Total number of individual fish stocked from Beaver Creek (B), Garvin Brook (G) and Cold Spring Brook (C) from 2003 to 2005 . In 2003 and 2005, 50 fish were stocked from each source. In 2004, few sculpins were stocked from Cold Spring Brook; the number from each source is in parentheses

b This is across eight microsatellite loci for source (s) and reintroduced (r) populations. Sample sizes $(n)$ and mean values across all loci for the overall inbreeding coefficient $\left(\mathrm{F}_{\mathrm{IS}}\right)$, expected $\left(\mathrm{H}_{\mathrm{E}}\right)$ and observed $\left(\mathrm{H}_{\mathrm{O}}\right)$ heterozygosity, simulated heterozygosity, allelic richness and simulated allelic richness. Populations are sorted from lowest to highest richness

\section{Sampling}

Sampling for the genetic analysis was conducted in autumn 2007 at all source and recipient sites except Pickwick Creek, which was sampled in autumn 2008. Fish were collected using a Wisconsin ${ }^{\mathrm{TM}}$ Abp-3 pulsed DC backpack electrofisher with power output settings adjusted to minimize negative effects on the reintroduced fish (Cowx and Lamarque 1990). Each fish was lightly anesthetized using tricaine methanosulfate (Summerfelt and Smith 1990), weighed, and measured for standard length. A small amount of tissue was clipped from the left pelvic fin of each fish and preserved in 95\% ethanol for genetic analysis. After processing, fish were returned to a recovery bucket with fresh water and eventually returned to the stream. None of the originally stocked fish were resampled in this dataset because all reintroduced fish were marked with a fin clip upon their release and none was recaptured.

\section{DNA extraction and amplification}

We used eight microsatellite loci developed for other Cottus species that resolved genetic variation in C. cognatus: Cgo18, Cgo42, Cgo310, and Cgo1033 (Englbrecht et al. 1999); Cott290, Cott686, and CottES1 (Nolte et al. 2005b); and Cba14 (Fiumera et al. 2002). We prepared samples for polymerase chain reaction (PCR) amplification using a simple DNA extraction procedure. A small sliver of fin tissue (approximately $1 \mathrm{~mm}^{2}$ ) was placed in a $1.5 \mathrm{ml}$ tube with $250 \mathrm{ml}$ of a $5 \%$ solution of a chelating resin $\left(\right.$ Chelex $^{\circledR}$, Sigma Chemical, St. Louis, MO). Samples were incubated overnight in a $56^{\circ} \mathrm{C}$ water bath and boiled $8 \mathrm{~min}$. Microsatellite amplification was performed in $15 \mu \mathrm{l}$ reactions containing $1 \times$ polymerase buffer $(10 \mathrm{mM}$ Tris- $\mathrm{HCl}$, $50 \mathrm{mM} \mathrm{KCl}, 0.1 \%$ Triton $\left.^{\circledR} \mathrm{X}-100\right), 1.5 \mathrm{mM} \mathrm{MgCl}_{2}$, $0.2 \mathrm{mM}$ each dNTP, $0.5 \mu \mathrm{M}$ of the forward and reverse primers, with the forward primer labeled with a fluorescent dye 6FAM, VIC, NED or PET, and 0.5 units Taq DNA polymerase (Promega, Madison, WI). Loci were combined into three multiplexed reactions: Cba14, CottES1, Cott290 and Cott686; Cgo18 and Cgo310; and $\mathrm{Cgo} 42$ and Cgo1033. Each set of samples included a water blank as a negative control to detect possible contamination of PCR solutions. Amplification was carried out in a thermocycler (Hybaid Omn-E, Thermo-Hybaid U.S., Franklin, MA) with 35 cycles at the following temperature profile: $95^{\circ} \mathrm{C}$ for $30 \mathrm{~s}, 50^{\circ} \mathrm{C}$ for $30 \mathrm{~s}$, and $72^{\circ} \mathrm{C}$ for $1 \mathrm{~min}$; followed by a 20 min extension at $72^{\circ} \mathrm{C}$. We submitted PCR products to the Biomedical Genomics Center (University of Minnesota, St. Paul) for electrophoresis on an ABI Prism 3130xl Genetic Analyzer (Applied Biosystems, Foster City, CA). We scored alleles using the software program GENOTYPER 2.5 (Applied Biosystems 2001).

Genetic diversity analysis

We evaluated several aspects of the genetic diversity within each sample, including allelic richness, the 
inbreeding coefficient $\left(\mathrm{F}_{\mathrm{IS}}\right)$, which measures the degree of inbreeding due to the mating system, and the observed $\left(\mathrm{H}_{\mathrm{O}}\right)$ and expected $\left(\mathrm{H}_{\mathrm{E}}\right)$ heterozygosities. Allelic richness, a measure of allele counts adjusted to a common sample size, was calculated using rarefaction techniques in HPRare (Kalinowski 2005). F-statistics were calculated and conformance with Hardy-Weinberg expectations was tested for each locus in each sample using the exact test (Guo and Thompson 1992), as implemented in GENEPOP v4.0.4 (Raymond and Rousset 1995) using 10,000 dememorizations, 20 batches, and 500 iterations per batch. GENEPOP was also used to test for linkage disequilibrium between pairs of loci. Significance values for both tests were adjusted using sequential Bonferroni procedures (Rice 1989). Data from the three source populations were evaluated in MICROCHECKER v2.2.3 to detect evidence of null alleles or scoring errors due to large allele drop-out (Van Oosterhout et al. 2004).

We modeled the genetic diversity that the reintroduced populations might obtain after one generation, assuming random mating and equal reproductive success, using a computer program written as function scripts implemented in the R language (Ihaka and Gentleman 1996). Allele frequencies at each of the eight microsatellite loci were calculated using baseline data from the three source populations. Alleles were then chosen randomly for each locus in proportion to their occurrence in the source populations to artificially generate multilocus genotypes for the total number of diploid individuals that were stocked at a given site from each source population (Table 1). These individuals were pooled and a 1:1 ratio of males to females was designated randomly in this population. A male and a female were randomly drawn without replacement and haploid gametes were then extracted by randomly selecting one of the two copies at each locus. Each artificial "sperm" and "egg" was combined randomly until enough offspring were created to replace all of the parents. The family size of each pairing was chosen randomly from a Poisson distribution with a mean of two. Fifty of these offspring were randomly chosen and used to quantify allelic richness and heterozygosity values to simulate the rarefaction method used to calculate genetic variation statistics from our actual data. This entire process was looped 500 times for each reintroduced population to produce means and error estimates. These function scripts may be obtained from the senior author upon request.

Ancestry analysis

The contribution of each source population to the recipient populations was estimated using the Bayesian clustering algorithm implemented in the program STRUCTURE (V. 2.2.3; Pritchard et al. 2000; also refer to http://pritch.bsd.uchicago.edu). The number of populations $(\mathrm{K})$ was set to 3 , the known number of genetically distinct source populations, with an admixture model and correlated allele frequencies. The program was run with a 50,000 burn-in period followed by 100,000 Monte Carlo simulations. Baseline individuals were included in the runs without population identification to assist resolution of genetically differentiated clusters and determine the ability of STRUCTURE to correctly determine the ancestry of known fish. The contribution of each source population was estimated by the proportion of membership assigned to each of the $\mathrm{K}$ populations across all individuals in a recipient site sample, and using the known baseline fish to determine the correspondence of the STRUCTURE-determined populations and the known sources. Expected overall ancestry values were the proportions of each source population stocked at the recipient sites.

We also determined ancestry for individual fish and categorized them into nine crosstypes: pure strain (Beaver, Garvin, and Cold Spring), $\mathrm{F}_{1}$ generation hybrids (Beaver $\times$ Garvin, Beaver $\times$ Cold Spring, Cold Spring $\times$ Garvin) and advanced generation crosses, which include $\mathrm{F}_{2}$ hybrids and back-crosses (Beaver $\times$ Garvin, Beaver $\times$ Cold Spring, Beaver $\times$ Garvin $\times$ Cold Spring, Garvin $\times$ Cold Spring). Because reintroduced populations were sampled within a few years of stocking, the software NewHybrids (Anderson and Thompson 2002) was used to classify individual fish according to pure strain or hybrid categories assuming that only first- or second-generation descendents of founders were present. Individual classification required a two-step process because NewHybrids allows only two parental populations. First, for each source population individuals were removed from the dataset if STRUCTURE indicated they had a low probability of ancestry $(<0.125$ for populations with second generation descendents and $<0.25$ for Pickwick and Little Pickwick sites, that only had first generation descendents) from that source. If all three sources contributed ancestry, the individual was classified as $\mathrm{B} \times \mathrm{G} \times \mathrm{C}$ and not included in a NewHybrids dataset. Then, for each dataset containing fish from only two source populations, the probability that each fish was either from one source or a hybrid cross $\left(\mathrm{F}_{1}, \mathrm{~F}_{2}\right.$ or backcross) was determined using NewHybrids. Baseline individuals from the two appropriate sources were included in the analyses. Each run had a 50,000 burn-in period followed by 150,000 simulations, using the Jeffreys prior option for allele frequencies and mixing proportions. Runs were repeated using different seeds to verify that consistent solutions were found. Individuals were classified into a parental or hybrid category if their probability of membership was greater than or equal to 0.70 ; otherwise the specific classification of the individual was considered 
uncertain. Because second-generation hybrids were difficult to distinguish, probabilities of membership to the $F_{2}$ and backcross categories were combined into one category called "advanced-generation mixtures."

Expected cross type proportions were estimated using a multinomial distribution based on the proportions of each strain that were stocked assuming equal survival and reproduction with individual replacement (i.e. no population growth in proceeding generations) for two generations beyond stocking. The first generation only consisted of pure strain and $F_{1}$ hybrids and the second generation included the advanced-generation mixtures in addition to the first generation crosstypes. Expected proportions were based on equal numbers of individuals from both generations. The two Pickwick sites only included first generation crosstypes in the expected estimate because of the timing of stocking relative to sampling. Statistical assessment of the difference between expected and observed values for each category were made using the Median test (Zar 1999), a version of the Kruskal-Wallis ANOVA that frames the computation in terms of a contingency table.

We used transformed fixation index $\left(\mathrm{F}_{\mathrm{ST}}\right)$ estimates $\left(-\ln \left[\mathrm{F}_{\mathrm{ST}}-1\right]\right)$ (Reynolds et al. 1983) among pairs of reintroduced and source populations to generate a cluster dendrogram using the flexible- $\beta$ algorithm with $\beta=-0.7$ implemented in PC-ORD (Legendre and Legendre 1998; McCune and Mefford 1999).

\section{Results}

\section{Genetic diversity}

No source population deviated from Hardy-Weinberg Equilibrium (HWE) at any locus, and MICROCHECKER provided no evidence for null alleles or allele drop-out. In contrast, all reintroduced populations showed significant deviation from HWE (heterozygote excess or deficiency) at one or more loci (Table S1-supplementary material). Inbreeding coefficients $\left(F_{\text {IS }}\right)$ ranged from -0.25 to 0.25 across all loci, but there were no clear patterns in heterozygote excesses or deficits among reintroduced populations. Overall $\mathrm{F}_{\mathrm{IS}}$ values at the source streams (Table 1) were all slightly negative.

There were significant differences among the populations in both $\mathrm{H}_{\mathrm{O}}$ (ANOVA; main effects: population, locus; $F(11$, $77)=7.62, P \ll 0.001$ ) and allelic richness (ANOVA; main effects: population, locus; $F(11,77)=10.94$, $P \ll 0.001$ ) (Fig. 2). Allelic richness (Table S1-supplementary material) among loci ranged from 1.0 to 15.1 , and was higher for the reintroduced populations (mean $=6.4$ ) than for the source populations (mean $=4.1$ ). Of the source sites, Cold Spring had the lowest heterozygosity and allelic


Fig. 2 Least-squares mean observed and simulated potential heterozygosity and allelic richness across eight microsatellite loci. Source populations, indicated with an asterisk, do not have simulated values. Error bars represent $95 \%$ confidence intervals about the least-squares site-based error component (Weisberg 2005)

richness, whereas Beaver had the highest (Table 1). Overall, heterozygosity and allelic richness at the reintroduction sites was only slightly higher than for the Beaver source population (Fig. 2). Simulated $\mathrm{H}_{\mathrm{O}}$ was generally similar to $\mathrm{H}_{\mathrm{O}}$ in the reintroduction populations, while simulated allelic richness was higher than all nine reintroduced populations (Table 1).

\section{Patterns of ancestry}

Overall ancestry determined using STRUCTURE (Table 2; Fig. S1-supplementary material) indicated that a higher than expected proportion of ancestry from the Beaver population occurred in all but one of the reintroduction sites. Cold Spring and Garvin ancestry generally occurred in lower proportions than expected, but each considerably exceeded expectations in a few locations. For example, Cold Spring ancestry was $17 \%$ greater than expected at the Hay Creek reintroduction site and Garvin ancestry was 14 and $11 \%$ greater at Pickwick Creek and Rock Creek reintroduction sites, respectively. These large deviations were 
Table 2 Observed versus expected average proportions of source ancestry in each of the recipient streams

\begin{tabular}{|c|c|c|c|c|c|c|c|c|c|}
\hline Population & $\mathrm{B}_{\mathrm{OBS}}$ & $\mathrm{B}_{\mathrm{EXP}}$ & $O-E$ & $\mathrm{C}_{\mathrm{OBS}}$ & $\mathrm{C}_{\mathrm{EXP}}$ & $O-E$ & $\mathrm{G}_{\mathrm{OBS}}$ & $\mathrm{G}_{\mathrm{EXP}}$ & $\mathrm{O}-\mathrm{E}$ \\
\hline Latsch Creek & 73 & 42 & +31 & 4 & 17 & -12 & 23 & 42 & -19 \\
\hline Sugar Loaf Creek & 61 & 42 & +20 & 10 & 17 & -7 & 29 & 42 & -13 \\
\hline Gilbert Creek & 55 & 36 & +19 & 20 & 26 & -6 & 25 & 37 & -13 \\
\hline Little Pickwick Creek & 51 & 33 & +18 & 15 & 33 & -18 & 34 & 33 & +1 \\
\hline Trout Brook & 56 & 40 & +15 & 27 & 22 & +5 & 17 & 37 & -21 \\
\hline Klaire Creek & 53 & 40 & +13 & 13 & 17 & -4 & 34 & 43 & -9 \\
\hline Pickwick Creek & 44 & 33 & +11 & 8 & 33 & -25 & 47 & 33 & +14 \\
\hline Rock Creek & 44 & 42 & +2 & 4 & 17 & -13 & 52 & 41 & +11 \\
\hline Hay Creek & 32 & 39 & -8 & 39 & 22 & +17 & 29 & 38 & -10 \\
\hline Overall & 52 & 39 & +14 & 16 & 23 & -7 & 32 & 39 & -6 \\
\hline
\end{tabular}

Observed values are based on results from STRUCTURE ancestry assignment. Expected ancestry assumes an equal contribution from each source that is proportional to the number of individuals from each source population that were stocked in a given reintroduction site (see Table 1). Populations are sorted from highest to lowest proportion of Beaver Creek ancestry. Table values are percentages

The third column in each group $(\mathrm{O}-\mathrm{E})$ is the expected subtracted from the observed ancestry for each population

$B$ Beaver Creek, $G$ Garvin Brook, $C$ Cold Spring Brook

apparent even though bias tended to equalize ancestry estimates among sources. The known source samples analyzed using STRUCTURE each had 2-4\% assignment error (ancestry was assigned to one of the other two sources). Because these errors were approximately symmetrical among sources, ancestry estimates were biased toward less prevalent ancestry, such as Cold Spring. Indeed, at Latsch Creek and Rock Creek reintroduction sites overall estimates indicated 4\% Cold Spring ancestry, but no individuals appeared to be Cold Spring descendants based on low levels of assignment to Cold Spring ancestry and a lack of Cold Spring specific alleles.
Individual ancestry analysis (Table 3; Fig. 3) revealed that there were more sculpins of pure Beaver ancestry at the reintroduction sites (mean $=27 \%$ ) than any other cross type. The number of Beaver individuals was significantly greater than expected based on the number that were stocked (Median test; median $=0.111, \quad \chi^{2}=14.40$, $P=0.0001$ ), while Cold Spring (Median test; median $\left.=0.014, \chi^{2}=3.60, P=0.0578\right)$ and Garvin $\times$ Cold Spring advanced-generation mixtures (Median test; median $\left.=0.216, \chi^{2}=5.56, P=0.0184\right)$ occurred at significantly lower frequencies than expected. Garvin pure strain fish were on average less abundant than Beaver

Table 3 Individual ancestry by cross type at reintroduction sites

\begin{tabular}{|c|c|c|c|c|c|c|c|c|c|c|c|}
\hline Population & $\mathrm{B}$ & G & $\mathrm{C}$ & $\begin{array}{l}F_{1}: \\
B \times G\end{array}$ & $\begin{array}{l}\mathrm{F}_{1}: \\
\mathrm{B} \times \mathrm{C}\end{array}$ & $\begin{array}{l}F_{1}: \\
G \times C\end{array}$ & $\begin{array}{l}\text { Adv: } \\
B \times G\end{array}$ & $\begin{array}{l}\text { Adv: } \\
\mathrm{B} \times \mathrm{C}\end{array}$ & $\begin{array}{l}\text { Adv: } \\
B \times G \times C\end{array}$ & $\begin{array}{l}\text { Adv: } \\
G \times C\end{array}$ & $\mathrm{U}$ \\
\hline Latsch Creek & 54 & 1 & 0 & 4 & 0 & 0 & 22 & 0 & 0 & 0 & 19 \\
\hline Pickwick Creek & 37 & 13 & 1 & 34 & 13 & 3 & 0 & 0 & 0 & 0 & 0 \\
\hline Sugar Loaf Creek & 35 & 2 & 1 & 4 & 9 & 0 & 37 & 0 & 0 & 0 & 12 \\
\hline Klaire Creek & 28 & 3 & 0 & 3 & 0 & 14 & 21 & 2 & 10 & 0 & 19 \\
\hline Gilbert Creek & 23 & 1 & 1 & 16 & 2 & 0 & 4 & 17 & 15 & 4 & 18 \\
\hline Little Pickwick Cr. & 21 & 20 & 3 & 32 & 15 & 8 & 0 & 0 & 0 & 0 & 0 \\
\hline Rock Creek & 19 & 25 & 0 & 19 & 0 & 0 & 14 & 0 & 0 & 0 & 23 \\
\hline Trout Brook & 17 & 3 & 1 & 8 & 1 & 0 & 3 & 42 & 18 & 1 & 7 \\
\hline Hay Creek & 5 & 5 & 4 & 1 & 1 & 0 & 1 & 22 & 26 & 28 & 9 \\
\hline Mean & 27 & 8 & 1 & 13 & 4 & 3 & 11 & 9 & 8 & 4 & 12 \\
\hline
\end{tabular}

Populations are sorted from highest to lowest proportion of Beaver Creek ancestry. "Adv" designates a combination of advanced generation mixtures including $\mathrm{F}_{2}$ hybrids and both back-crosses. Unknown values are due to low probability of assignment to any crosstype. Pickwick and Little Pickwick sites had no advanced crosstypes because of the recent timing of stocking. Table values are percentages of individuals per crosstype

$B$ Beaver Creek, $G$ Garvin Brook, $C$ Cold Spring Brook, $U$ unknown 


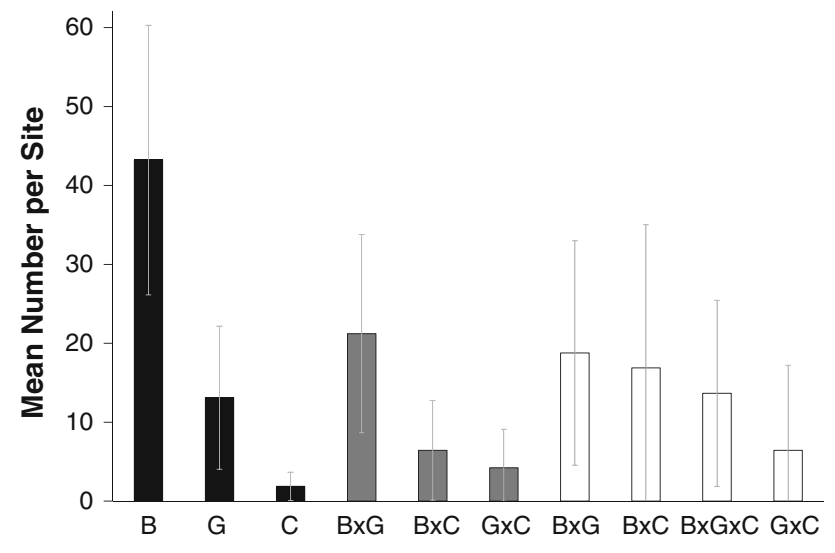

Fig. 3 Persistence of sculpin crosstypes at recipient sites $(B$ Beaver Creek, $G$ Garvin Brook, $C$ Cold Spring Brook). Bars indicate the mean number of individuals. Black bars indicate pure strain individuals; grey bars indicate $\mathrm{F}_{1}$ generation hybrid individuals; white bars indicate advanced generation mixtures such as $\mathrm{F}_{2}$ or back-cross individuals. Error bars represent $95 \%$ confidence intervals about the mean

(mean $=8 \%)$ and there were relatively few fish of pure Cold Spring ancestry $($ mean $=1 \%)$. Beaver $\times$ Garvin was the most abundant $\mathrm{F}_{1}$-hybrid type $($ mean $=13 \%)$ and Beaver $\times$ Cold Spring and Garvin $\times$ Cold Spring were similar in abundance (mean $=3-4 \%$ ). All of the advanced generation mixtures accounted for a total of $32 \%$ of the fish and $12 \%$ of the fish were of uncertain origin. Although fish of pure strain Cold Spring ancestry were rare at the reintroduction sites, overall Cold Spring ancestry was represented in roughly the same proportion as Garvin ancestry (Table 2) because $F_{1}$ and advanced generation mixtures that contained Cold Spring ancestry were abundant.
Errors in assigning individual crosstypes may have occurred at two occasions, when the dataset was reduced to include only two source ancestries at a time and when the remaining individuals were classified into crosstypes. Simulated genotypes run in Structure indicated low rates of erroneous inclusion $(<1 \%)$ in reduced two-ancestry datasets for all crosstypes except advanced generation crosstypes involving all three ancestries. $F_{1}, F_{2}$ and advanced generation crosstypes involving only two ancestries were incorrectly designated as advanced Beaver $\times$ Garvin $\times$ Cold Spring at rates of $0.1-5 \%$ while $11-15 \%$ of simulated advanced Beaver $\times$ Garvin $\times$ Cold Spring were incorrectly included in reduced two-ancestry datasets. Simulations for each pair of sources (Beaver and Garvin, Beaver and Cold Spring, Garvin and Cold Spring) in NewHybrids estimated error rates of 0-6\% for Beaver, Garvin, Cold Spring and $F_{1}$ crosstypes; all errors assigned to advanced generation crosstypes. For advanced generation crosstypes, $1-4 \%$ of $\mathrm{G} \times \mathrm{C}$ and $4-12 \%$ of Beaver $\times$ Garvin and Beaver $\times$ Cold Spring assigned to Beaver, Garvin, Cold Spring or $\mathrm{F}_{1}$.

Pairwise $\mathrm{F}_{\mathrm{ST}}$ values indicate substantial genetic differentiation among the three source populations (Garvin vs. Cold Spring, $\mathrm{F}_{\mathrm{ST}}=0.56$; Beaver vs. Cold Spring, $\mathrm{F}_{\mathrm{ST}}=$ 0.48; Beaver vs. Garvin, $\mathrm{F}_{\mathrm{ST}}=0.32$ ). A dendrogram, generated from pairwise $\mathrm{F}_{\mathrm{ST}}$ estimates, indicated distinct divisions that corresponded with the three source populations (Fig. 4). The reintroduced populations all clustered with Beaver and were relatively similar, although $\mathrm{F}_{\mathrm{ST}}$ estimates among all pairwise comparisons were significant $(P<0.05)$.

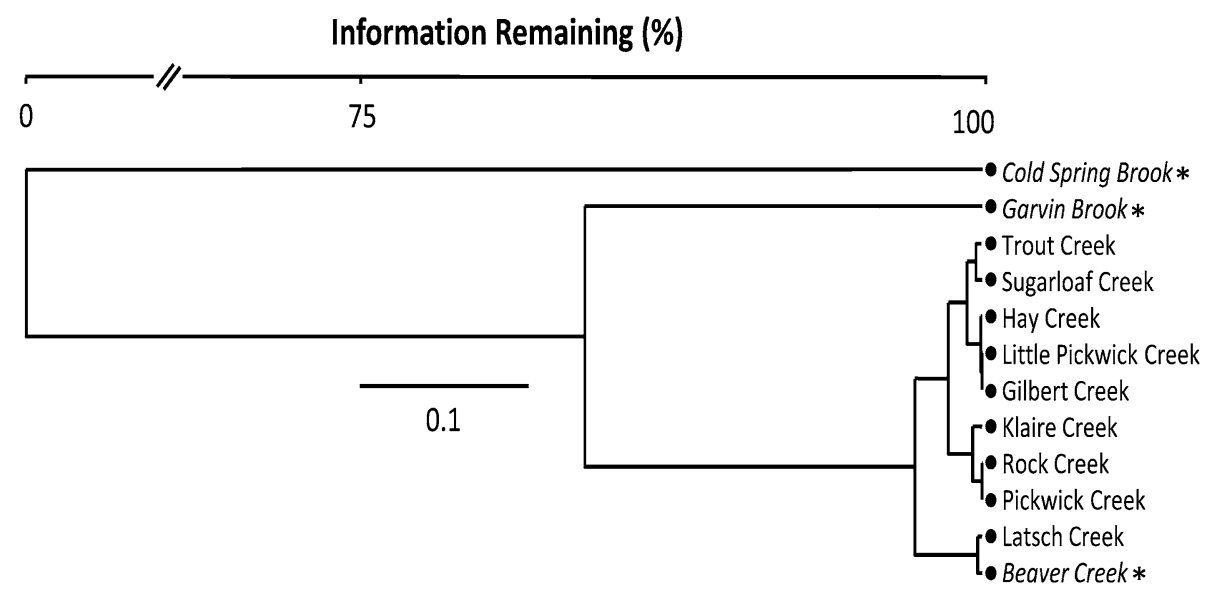

Fig. 4 Summary of genetic divergence among populations derived from agglomerative cluster analysis, using flexible beta linkage, of transformed pairwise $\mathrm{F}_{\mathrm{ST}}$ estimates (i.e. $-\ln \left[\mathrm{F}_{\mathrm{ST}}-1\right]$ ) based on eight microsatellite loci. Branch lengths are proportional to the degree of divergence among populations and are indicated by the $\mathrm{F}_{\mathrm{ST}}$ distance scale bar. "Percent Information Remaining" indicates the among-group variance explained as agglomeratin proceeds (McCune et al. 2002). Source populations are italicized and indicated with an asterisk 


\section{Discussion}

Reintroductions and genetic diversity

The few reports that describe levels of genetic diversity in slimy sculpin populations (Zimmerman and Wooten 1981; Strauss 1986) indicate that it generally tends to be low. This is presumably the result of isolation, small population sizes, and low vagility, among other potential causes (Fiumera et al. 2002). Genetic diversity potentially affects a variety of population and community processes. Our understanding of its effects depends on the relationship between measured variation in putatively neutral markers and the magnitude of variation in phenotypic traits. In some cases, phenotypic characteristics within populations that correspond to ecologically relevant traits and neutral genetic variation are correlated (Reed and Frankham 2001). More genetically diverse mixtures of reintroduced animals will have a higher probability of including a genotype that is more productive in a novel environment, such as a reintroduction site (Barrett and Schluter 2008). Mixedsource reintroductions in our study, however, resulted in mean heterozygosity and allelic richness levels across all sites that were only slightly higher than those found at the Beaver source site. Simulated heterozygosities were comparable to the observed values, whereas simulated allelic richness values were only moderately higher (mean $=$ $+12 \%$ ). Our expectation was that simulated values would be much higher than the observed values because our simulations were designed to mimic ideal circumstances for high genetic variation: equal survival, random mate choice and reproductive success, and measurement of genetic variation in the first generation after stocking. Our simulations also indicated that, at best, we would only expect a moderate increase in heterozygosity and allelic richness beyond levels in Beaver, the highest diversity source population. A similar result was reported for reintroductions using the ibex, Capra ibex as a model species (Maudet et al. 2002). The fact that observed diversity levels are as high as they are is a bit surprising because some combination of differential fitness, assortative mating, or other factors led to asymmetrical ancestral proportions that favored the Beaver strain. Enhanced diversity came especially from the relatively abundant admixed individuals at some sites. Although Garvin and Cold Spring populations had lower diversity overall, they had multiple unique alleles. Interpopulation crosses would have increased allelic richness and produced more heterozygotes compared with the Beaver population alone.

The two sites stocked most recently, Pickwick Creek and Little Pickwick Creek, had the highest allelic richness. A reasonable explanation is that these populations, with only first-generation descendents of stocked fish, lost fewer rare alleles due to drift. The other populations with secondgeneration descendents would have been susceptible to additional drift losses. After a few generations, the decrease in allelic richness should slow as there are fewer rare alleles left to be lost (Nei et al. 1975). Except for higher richness in the Pickwick populations, there were no other strong trends in genetic diversity measures versus the number of successive stocking events.

Although all of the reintroduced populations indicated significant deviations from HWE, the lack of a clear pattern across markers and sites in heterozygote deficiency or excess is likely due to the complexity of effects that are interacting at the sites. For example, heterozygote excesses could arise from disassortative mating among strains or differences in allele frequencies among males and females in populations with small effective size (Allendorf and Luikart 2007). Heterozygote deficits could arise from within-strain mate choice or demic structure that corresponds to ancestral origins because of heritable differences among stocks in characteristics, such as habitat preference for spawning and timing of spawning (Ryman et al. 1979). Furthermore, selection acting on homozygous or heterozygous genotypes associated with strain crosses could also cause excess or deficits. Although departures from HWE are difficult to explain, they may suggest strain differences in mating systems, behavior, and survival and therefore warrant further investigation. Many microsatellite loci deviated from HWE in the reintroduced populations, whereas there were no significant deviations from HWE in the source populations. These deviations from HWE up to two generations after reintroduction suggest barriers to admixture, as HWE should be achieved in the first generation of random mating and a heterozygote advantage would produce heterozygote excesses broadly (Allendorf and Luikart 2007). Locus-specific effects on fitness at the reintroduction sites (Nolte et al. 2009), in addition to previously mentioned dynamics, could obscure a broad pattern of heterozygote deficits.

\section{Reintroductions and patterns of ancestry}

Even minor differences in the relative fitness of introgressant lineages can lead to noticeably different admixture rates (Epifanio and Philipp 2000). Beaver ancestry was over-represented at eight of nine populations, often by a substantial margin (Table 2), whereas both Cold Spring and Garvin ancestry was under-represented with a few exceptions. Possible explanations that could operate alone or simultaneously to explain the differential success of the Beaver strain include an adaptive advantage in the Beaver strain, or inbreeding depression in the Garvin and Cold Spring strains. Simultaneous inbreeding and outbreeding depression has been demonstrated in animal populations 
(Marshall and Spalton 2000) and may be especially common in fish species that exhibit philopatry or low vagility (Neff 2004). The first possibility is that an adaptation to local conditions in Beaver Creek is advantageous at a majority of the reintroduction sites, thereby conferring a selective advantage upon sculpins with Beaver ancestry. In this case, a significantly higher proportion of pure strain Beaver fish would be expected across all or most reintroduction sites. The other two strains may reduce the fitness of the Beaver strain through introgression by disrupting beneficial gene complexes or local adaptations. This explanation is consistent with our analysis because pure strain Beaver sculpins were persistent in high proportions at nearly all of the reintroduction sites even though nearly complete admixture with the other two strains after a few generations would have been expected (Epifanio and Philipp 2000).

An alternative to adaptive differences among strains is that there are disadvantages in the Cold Spring and Garvin strains as a result of inbreeding depression. This scenario predicts that pure strain Cold Spring and Garvin individuals would perform poorly across all sites and that heterosis could occur in $F_{1}$ hybrids and advanced generation mixtures. There were relatively few pure strain Cold Spring and Garvin individuals that persisted, but overall ancestry was similar or only slightly lower than expected given the number of these fish that were originally stocked. Mixedancestry descendents could have benefited from increased heterozygosity that alleviated inbreeding depression. However, pure Garvin and Cold Spring individuals occurred in relatively high numbers at one or more reintroduction sites and are abundant at the source streams (Huff 2010), which indicates a lack of widespread, severe inbreeding depression in these strains.

Classification errors in determining crosstypes were unlikely to alter our major observations and conclusions. The strong differentiation among source populations provided high power to distinguish crosstypes. Simulations indicated some potential bias toward reduced estimates of advanced $\mathrm{B} \times \mathrm{G} \times \mathrm{C}$ crosstypes when reducing datasets to two source ancestries and toward reduced estimates of advanced $\mathrm{B} \times \mathrm{G}$ and $\mathrm{B} \times \mathrm{C}$ and conversely increased estimates of $\mathrm{B}, \mathrm{G}, \mathrm{C}$ and $\mathrm{F}_{1}$ when assigning crosstypes. Contrary to the potential biases, estimates of $\mathrm{G}, \mathrm{C}$ and $\mathrm{F}_{1}$ crosstypes were all less than expected.

\section{Cluster analysis}

Summary of genetic divergence among populations using $\mathrm{F}_{\mathrm{ST}}$ values or genetic distance measures (Pasko and Maslak 2003; Mock et al. 2004; Latch and Rhodes 2005) should be used cautiously when attempting to determine the origin of potentially mixed-source reintroductions. The mean value represented by $\mathrm{F}_{\mathrm{ST}}$ can be misleading because a presumed population may remain a conglomeration of distinct syntopic populations for many generations. Our dendrogram (Fig. 4) indicated that the reintroduced populations are most similar to, or retained the "genetic signature," of the Beaver source population. In reality, the genetic composition of the reintroduced sites is a mixture of various pure strain and interpopulation hybrids unlike that found at Beaver. Mixtures of distinct strains are of concern when relying on population assignment techniques to describe the composition of populations. Assigning individuals to a single source population based on the highest proportion of ancestry alone oversimplifies the situation and ignores the possibility of hybridization (e.g. Latch and Rhodes 2005) and hybrids can have very different fitness than their parental strains (Edmands and Timmerman 2003). By determining the ancestry of individuals with an admixture model, we avoided these issues and were able to represent the complexity of the ancestral composition in the reintroduction populations.

\section{Reintroductions: one versus multiple sources}

Generally, one of the primary concerns in reintroduction is to preserve genetic diversity (Meffe 1995; Minckley 1995). But the decision whether or not to mix source populations depends on the existing scale and degree of isolation among the candidate source populations. Moritz (1999) has suggested that the threshold for preservation of a distinct population is signified by reciprocal monophyly as determined by mtDNA haplotypes, in addition to divergence of allele frequencies at nuclear loci. Others argue that evidence of ecological divergence is sufficient to warrant actions to preserve an intact genetically distinct population (Crandall et al. 2000). These issues continue to be actively debated (Zink 2007). Moreover, genetic divergence should be assessed both spatially and temporally to assure that high divergence does not result from rapid genetic drift in small, isolated populations. If this is the case, then mixing sources may be appropriate. If potentially adaptive trait differences are observed, and pilot studies in which reintroduced populations may be monitored are feasible, then phenotypic plasticity may be parsed out from genetically based local adaptation via common garden or reciprocal transplant experiments that measure differences in phenotypic traits (e.g., growth, body size, fecundity and survivorship; Rader et al. 2005).

Slimy sculpins require very cold water and occur at the warmer southern limits of their range in the Driftless Region. Given the precarious long-term persistence of cold water habitat globally (Meisner 1990b; Magnuson and Destasio 1997), the choice to preserve individual populations in the Driftless Region may be considered by some managers as subordinate to the necessity to maximize 
genetic diversity within the region. Mixing populations is more likely to provide adaptive potential for reintroductions, increase genetic diversity, and alleviate inbreeding depression. This would be especially appropriate if the scale of genetic and ecological uniqueness of slimy sculpins exists within the Driftless Region as a whole rather than among isolated populations within it. Using a single source or mixing sources depends not only on the characteristics of the populations but also on the condition of the reintroduction environment (Lesica and Allendorf 1999; Jones 2003). Intraspecific variation may be utilized to enhance the success of reintroductions in which complete habitat restoration is beyond the reach of natural resource managers. Hybrid mixtures among populations could be suitable for relatively disturbed sites that are unlikely to have a compatible "pre-adapted" source population, or if there is evidence of maladaptation (Crespi 2000), no local adaptation, or high phenotypic plasticity (Mittelbach et al. 1999).

On the other hand, if populations within the region represent long-isolated lineages, then these populations should not be mixed unless it is apparent that genetic rescue (Tallmon et al. 2004) is necessary. A critical challenge in the management of fragmented wild populations is calculating the risk of outbreeding depression (Frankham 2010). Evidence of ecological divergence among source populations should be carefully considered because it indicates the potential for disrupting unique local adaptations that may be worth preserving (Crandall et al. 2000), and for outbreeding depression in intrapopulation hybrid individuals. Because of the variation in habitat and their degree of isolation, sculpin populations in the Driftless Region may not only have a unique evolutionary history, but they may also not be ecologically exchangeable with one another (Crandall et al. 2000; Rader et al. 2005). Mixing these sources may have the disadvantage of disrupting unique adaptations among populations and lead to decreased fitness. Outbreeding depression has been shown to occur in a variety of fish species wherein unrelated populations were crossed (McClelland and Naish 2007). Unfortunately, the consequences of outbreeding are difficult to predict. For example, an interesting outcome of outbreeding has recently been documented for a closely related species, the European sculpin (Cottus gobio), in the River Rhine drainage in Germany (Nolte et al. 2005a). In this instance, anthropogenic removal of natural barriers between long separated lineages generated invasive intraspecific hybrids that were adapted to conditions unlike those of either parental strain.

\section{Conclusions}

Clearly there are tradeoffs associated with using one versus multiple sources in reintroductions. The time and expense involved in determining whether populations are ecologically or genetically divergent often requires that a decision be made without complete knowledge. Founders should be selected to reflect the original genetic composition to the extent it is possible (Moritz 1999; Frankham et al. 2002), and inbreeding depression is a concern because fitnessrelated traits may be negatively effected, eventually leading to extinction (Keller and Waller 2002). However, managers should seriously consider the risks of outbreeding before intentionally hybridizing populations (Epifanio and Philipp 2000; Edmands 2007). Although outbreeding depression could be a temporary phenomenon that will disappear if the population can survive the initial reduced fitness (Frankham et al. 2002), for small populations that reproduce slowly, even a temporary reduction in fitness may not be desirable. Furthermore, genetically divergent reintroduced populations may pose an outbreeding depression risk to nearby populations via gene flow.

An alternative to mixing sources would be to begin by evaluating the genetic characteristics of the candidate source populations. This is now more feasible because genetic techniques such as microsatellite analysis are becoming increasingly inexpensive and accessible. Hypothetical genetic diversity estimates could be made for various combinations of source populations so that the potential benefit in terms of increased genetic diversity could be quantified. If a single source is chosen, careful monitoring of reintroduced populations may identify the need for genetic rescue, which may simply be carried out through supplementation from different sources later on.

In this study, given the absence of information regarding deep phylogenetic separation among populations, the great degree of genetic differentiation, the potential for disrupting beneficial adaptations, and the lack of evidence that genetic rescue is necessary, the most conservative option available for future reintroductions of slimy sculpin in the Driftless Region would be to use a single source. Single source reintroductions may be carried out on a trial basis using local strains that maximize the likelihood of genetic and ecological similarity to inhabitants of the surrounding area. Monitoring the populations may identify the need to supplement the reintroduced populations with individuals from different strains if it is warranted.

Acknowledgments Special thanks to Christopher Chizinski for statistical advice and writing $\mathrm{R}$ code for diversity simulations. We would like to thank Ray Newman, Andrew Simons, Michele Koehler, Craig Primmer and two anonymous reviewers for helpful comments on the manuscript. Thanks to Eric Merten and Vaughn Snook for advice and field assistance. Funding was provided by a fellowship from Austen Cargill II; a doctoral dissertation fellowship by the Graduate School of the University of Minnesota; and the Minnesota Department of Natural Resources, U.S. Geological Survey Cooperative Research Units Program, and the Dayton-Wilkie Natural History Fund of the Bell Museum of Natural History. The Minnesota 
Cooperative Fish and Wildlife Research Unit is jointly sponsored by the U.S. Geological Survey, University of Minnesota, Minnesota Department of Natural Resources the U.S. Fish and Wildlife Service, and Wildlife Management Institute. Reference to trade names or products does not imply endorsement by the U.S. Government.

\section{References}

Allendorf FW, Luikart G (2007) Conservation and the genetics of populations. Blackwell, Malden

Anderson EC, Thompson EA (2002) A model-based method for identifying species hybrids using multilocus genetic data. Genetics 160:1217-1229

Bailey NW, Garcia CM, Ritchie MG (2007) Beyond the point of no return? A comparison of genetic diversity in captive and wild populations of two nearly extinct species of Goodeid fish reveals that one is inbred in the wild. Heredity 98:360-367

Barrett RDH, Schluter D (2008) Adaptation from standing genetic variation. Trends Ecol Evol 23:38-44

Bond CE (1963) Distribution and ecology of freshwater sculpins, genus Cottus, in Oregon. University of Michigan, Ann Arbor

Cowx IG, Lamarque P (1990) Fishing with electricity: applications in freshwater fisheries management. Fishing News Books, Oxford

Crandall KA, Bininda-Emonds ORP, Mace GM, Wayne RK (2000) Considering evolutionary processes in conservation biology. Trends Ecol Evol 15:290-295

Crespi BJ (2000) The evolution of maladaptation. Heredity 84:623-629

Edmands S (2007) Between a rock and a hard place: evaluating the relative risks of inbreeding and outbreeding for conservation and management. Mol Ecol 16:463-475

Edmands S, Timmerman CC (2003) Modeling factors affecting the severity of outbreeding depression. Conserv Biol 17:883-892

Ehrlich PR (1988) The loss of diversity: causes and consequences. In: Wilson EO (ed) Biodiversity. National Academy Press, Washington, DC, pp 21-27

Englbrecht CC, Largiader CR, Hanfling B, Tautz D (1999) Isolation and characterization of polymorphic microsatellite loci in the European bullhead Cottus gobio L-(Osteichthyes) and their applicability to related taxa. Mol Ecol 8:1966-1969

Epifanio J, Philipp D (2000) Simulating the extinction of parental lineages from introgressive hybridization: the effects of fitness, initial proportions of parental taxa, and mate choice. Rev Fish Biol Fish 10:339-354

Fischer J, Lindenmayer DB (2000) An assessment of the published results of animal relocations. Biol Conserv 96:1-11

Fitzsimmons NN, Buskirk SW, Smith MH (1997) Genetic changes in reintroduced Rocky Mountain bighorn sheep populations. J Wildl Manag 61:863-872

Fiumera AC, Porter BA, Grossman GD, Avise JC (2002) Intensive genetic assessment of the mating system and reproductive success in a semi-closed population of the mottled sculpin, Cottus bairdi. Mol Ecol 11:2367-2377

Foster SA, Baker JA, Bell MA (2003) The case for conserving threespine stickleback populations: protecting an adaptive radiation. Fisheries 28:10-18

Frankham R (2010) Challenges and opportunities of genetic approaches to biological conservation. Biol Conserv 143:19191927

Frankham R, Briscoe DA, Ballou JD (2002) Introduction to conservation genetics. Cambridge University Press, Cambridge

George AL, Kuhajda BR, Williams JD, Cantrell MA, Rakes PL, Shute JR (2009) Guidelines for propagation and translocation for freshwater fish conservation. Fisheries 34:529-545
Goyke AP, Hershey AE (1992) Effects of fish predation on larval chironomid (Diptera, Chironomidae) communities in an Arctic ecosystem. Hydrobiologia 240:203-211

Griffith B, Scott JM, Carpenter JW, Reed C (1989) Translocation as a species conservation tool-status and strategy. Science 245 : $477-480$

Guo SW, Thompson EA (1992) Performing the exact test of HardyWeinberg proportion for multiple alleles. Biometrics 48: 361-372

Holliday VT, Knox JC, Running GLI, Mandel RD, Ferring CR (2002) The Central Lowlands and Great Plains. In: Orme AR (ed) The physical geography of North America. Oxford University Press, Oxford, pp 335-362

Holsinger KE, Gottlieb LD (1989) The conservation of rare and endangered plants. Trends Ecol Evol 4:193-194

Honnay O, Jacquemyn H (2007) Susceptibility of common and rare plant species to the genetic consequences of habitat fragmentation. Conserv Biol 21:823-831

Huff DD (2010) Examining genetic diversity, hybrid fitness, and local adaptation in a native fish reintroduction program. In: Fisheries, wildlife and conservation biology. University of Minnesota, Saint Paul, p 128

Ihaka R, Gentleman R (1996) R: a language for data analysis and graphics. J Comput Graph Stat 5:239-314

IUCN (1998) IUCN guidelines for reintroductions. IUCN, Gland \& Cambridge

Jelks HL, Walsh SJ, Burkhead NM, Contreras-Balderas S, Díaz-Pardo E, Hendrickson DA, Lyons J, Mandrak NE, McCormick F, Nelson JS, Platania SP, Porter BA, Renaud CB, Schmitter-Soto JJ, Taylor EB, Warren ML (2008) Conservation status of imperiled North American freshwater and diaddromous fishes. Fisheries 33:372-407

Jones TA (2003) The restoration gene pool concept: beyond the native versus non-native debate. Restor Ecol 11:281-290

Kalinowski ST (2005) HP-RARE 1.0: a computer program for performing rarefaction on measures of allelic richness. Mol Ecol Notes 5:187-189

Keller LF, Waller DM (2002) Inbreeding effects in wild populations. Trends Ecol Evol 17:230-241

Lande R (1988) Genetics and demography in biological conservation. Science 241:1455-1460

Lande R (1998) Anthropogenic, ecological and genetic factors in extinction and conservation. Res Popul Ecol 40:259-269

Lande R, Barrowclough GF (1987) Effective population size, genetic variation, and their use in population management. In: Soule ME (ed) Viable populations for conservation. Cambridge University Press, Cambridge, pp 87-124

Latch EK, Rhodes OE (2005) The effects of gene flow and population isolation on the genetic structure of reintroduced wild turkey populations: are genetic signatures of source populations retained? Conserv Genet 6:981-997

Legendre P, Legendre L (1998) Numerical ecology, 2nd English edn. Elsevier, Amsterdam

Leopold A, Sewell M (2001) A Sand County almanac: with essays on conservation. Oxford University Press, New York

Lesica P, Allendorf FW (1999) Ecological genetics and the restoration of plant communities: mix or match? Restor Ecol 7:42-50

Magnuson JJ, Destasio BT (1997) Thermal niche of fishes and global warming. In: Wood CM, McDonald DG (eds) Global warming: implications for freshwater and marine fish. Cambridge University Press, Cambridge, pp 377-408

Marshall TC, Spalton JA (2000) Simultaneous inbreeding and outbreeding depression in reintroduced Arabian oryx. Anim Conserv 3:241-248

Maudet C, Miller C, Bassano B, Breitenmoser-Wursten C, Gauthier D, Obexer-Ruff G, Michallet J, Taberlet P, Luikart G (2002) 
Microsatellite DNA and recent statistical methods in wildlife conservation management: applications in Alpine ibex [Capra ibex (ibex)]. Mol Ecol 11:421-436

McClelland EK, Naish KA (2007) What is the fitness outcome of crossing unrelated fish populations? A meta-analysis and an evaluation of future research directions. Conserv Genet 8:397-416

McCune B, Mefford MJ (1999) PC-ORD multivariate analysis of ecological data. MJM Software Design, Gleneden Beach

McCune B, Grace JB, Urban DL (2002) Analysis of ecological communities. MJM Software Design, Gleneden Beach

Meffe GK (1995) Genetic and ecological guidelines for species reintroduction programs: application to Great Lakes fishes. J Gt Lakes Res 21:3-9

Meisner JD (1990a) Effect of climatic warming on the southern margins of the native range of brook trout, Salvelinus fontinalis. Can J Fish Aquat Sci 47:1065-1070

Meisner JD (1990b) Potential loss of thermal habitat for brook trout, due to climatic warming, in 2 southern Ontario streams. Trans Am Fish Soc 119:282-291

Miller RR, Williams JD, Williams JE (1989) Extinctions of NorthAmerican fishes during the past century. Fisheries 14:22-38

Minckley WL (1995) Translocation as a tool for conserving imperiled fishes-experiences in western United-States. Biol Conserv 72:297-309

Minckley WL, Deacon JE (1991) Battle against extinction: native fish management in the American West. University of Arizona Press, Tucson

Mittelbach GC, Osenberg CW, Wainwright PC (1999) Variation in feeding morphology between pumpkinseed populations: phenotypic plasticity or evolution? Evol Ecol Res 1:111-128

MNDNR (2003) Strategic plan for coldwater fisheries management in southeast Minnesota, 2004-2015. Minnesota Department of Natural Resources, St. Paul, pp 1-35

Mock KE, Latch EK, Rhodes OE (2004) Assessing losses of genetic diversity due to translocation: long-term case histories in Merriam's turkey (Meleagris gallopavo merriami). Conserv Genet 5:631-645

Moritz C (1999) Conservation units and translocations: strategies for conserving evolutionary processes. Hereditas 130:217-228

Neff BD (2004) Stabilizing selection on genomic divergence in a wild fish population. Proc Natl Acad Sci USA 101:2381-2385

Nei M, Maruyama T, Chakraborty R (1975) Bottleneck effect and genetic-variability in populations. Evolution 29:1-10

Nolte AW, Freyhof J, Stemshorn KC, Tautz D (2005a) An invasive lineage of sculpins, Cottus sp (Pisces, Teleostei) in the Rhine with new habitat adaptations has originated from hybridization between old phylogeographic groups. Proc R Soc Lond Ser B 272:2379-2387

Nolte AW, Stemshorn KC, Tautz D (2005b) Direct cloning of microsatellite loci from Cottus gobio through a simplified enrichment procedure. Mol Ecol Notes 5:628-636

Nolte AW, Gompert Z, Buerkle CA (2009) Variable patterns of introgression in two sculpin hybrid zones suggest that genomic isolation differs among populations. Mol Ecol 18:2615-2627

Pasko L, Maslak R (2003) Genetics of the peripheral populations of the alpine bullhead, Cottus poecilopus (Scorpaeniformes, Cottidae) in Poland. J Zool Syst Evol Res 41:196-204

Petrosky CE, Waters TF (1975) Annual production by slimy sculpin population in a small Minnesota trout stream. Trans Am Fish Soc 104:237-244

Pritchard JK, Stephens M, Donnelly P (2000) Inference of population structure using multilocus genotype data. Genetics 155:945-959

Rader RB, Belk MC, Shiozawa DK, Crandall KA (2005) Empirical tests for ecological exchangeability. Anim Conserv 8:239-247
Raymond M, Rousset F (1995) An exact test for population differentiation. Evolution 49:1280-1283

Reed DH, Frankham R (2001) How closely correlated are molecular and quantitative measures of genetic variation? A meta-analysis. Evolution 55:1095-1103

Reynolds J, Weir BS, Cockerham CC (1983) Estimation of the coancestry coefficient basis for a short-term genetic distance. Genetics 105:767-779

Rice WR (1989) Analyzing tables of statistical tests. Evolution 43:223-225

Ryman N, Allendorf FW, Stahl G (1979) Reproductive isolation with little genetic-divergence in sympatric populations of brown trout (Salmo trutta). Genetics 92:247-262

Saccheri I, Kuussaari M, Kankare M, Vikman P, Fortelius W, Hanski I (1998) Inbreeding and extinction in a butterfly metapopulation. Nature 392:491-494

Schmetterling DA, Adams SB (2004) Summer movements within the fish community of a small Montane stream. North Am J Fish Manag 24:1163-1172

Scott WB, Crossman EJ (1979) Freshwater fishes of Canada. Fisheries Research Board of Canada, Ottawa

Seddon PJ, Armstrong DP, Maloney RF (2007) Developing the science of reintroduction biology. Conserv Biol 21:303-312

Strauss RE (1986) Natural hybrids of the fresh-water sculpins Cottus bairdi and Cottus cognatus (Pisces, Cottidae)—electrophoretic and morphometric evidence. Am Midl Nat 115:87-105

Summerfelt RC, Smith LS (1990) Anesthesia, surgery and related techniques. In: Schreck CB, Moyle PB (eds) Methods for fish biology. American Fisheries Society, Bethesda, pp 213-272

Tallmon DA, Luikart G, Waples RS (2004) The alluring simplicity and complex reality of genetic rescue. Trends Ecol Evol 19:489-496

Templeton AR, Hemmer H, Mace G, Seal US, Shields WM, Woodruff DS (1986) Local adaptation, coadaptation, and population-boundaries. Zoo Biol 5:115-125

Tester JR, Keirstead M (1995) Minnesota's natural heritage: an ecological perspective. University of Minnesota Press, Minneapolis

Thorn WC, Anderson CS, Lorenzen WE, Hendickson DL, Wagner JW (1997) A review of trout management in southeast Minnesota streams. North Am J Fish Manag 17:860-872

Tilman D, Lehman CL, Yin CJ (1997) Habitat destruction, dispersal, and deterministic extinction in competitive communities. Am Nat 149:407-435

Van Oosterhout C, Hutchinson WF, Wills DPM, Shipley P (2004) MICRO-CHECKER: software for identifying and correcting genotyping errors in microsatellite data. Mol Ecol Notes 4:535-538

Waters TF (1977) The streams and rivers of Minnesota. University of Minnesota Press, Minneapolis

Weisberg S (2005) Applied linear regression, 3rd edn. Wiley/ Interscience

Williams JE, Sada DW, Williams CD (1988) American Fisheries Society guidelines for introductions of threatened and endangered fishes. Fisheries 13:5-11

Wolf CM, Griffith B, Reed C, Temple SA (1996) Avian and mammalian translocations: update and reanalysis of 1987 survey data. Conserv Biol 10:1142-1154

Zar JH (1999) Biostatistical analysis, 4th edn. Prentice Hall, Upper Saddle River

Zimmerman EG, Wooten MC (1981) Allozymic variation and natural hybridization in sculpins, Cottus confusus and Cottus cognatus. Biochem Syst Ecol 9:341-346

Zink RM (2007) Ecological exchangeability versus neutral molecular markers: the case of the great tit. Anim Conserv 10:369-373 